\title{
Prevention of infections associated with peripheral catheters: construction and validation of clinical scenario
}

\author{
Prevenção de infecções associadas a cateteres periféricos: construção e validação de cenário clínico
}

Prevención de infecciones relacionadas a catéteres periféricos: construcción y validación de escenario clínico

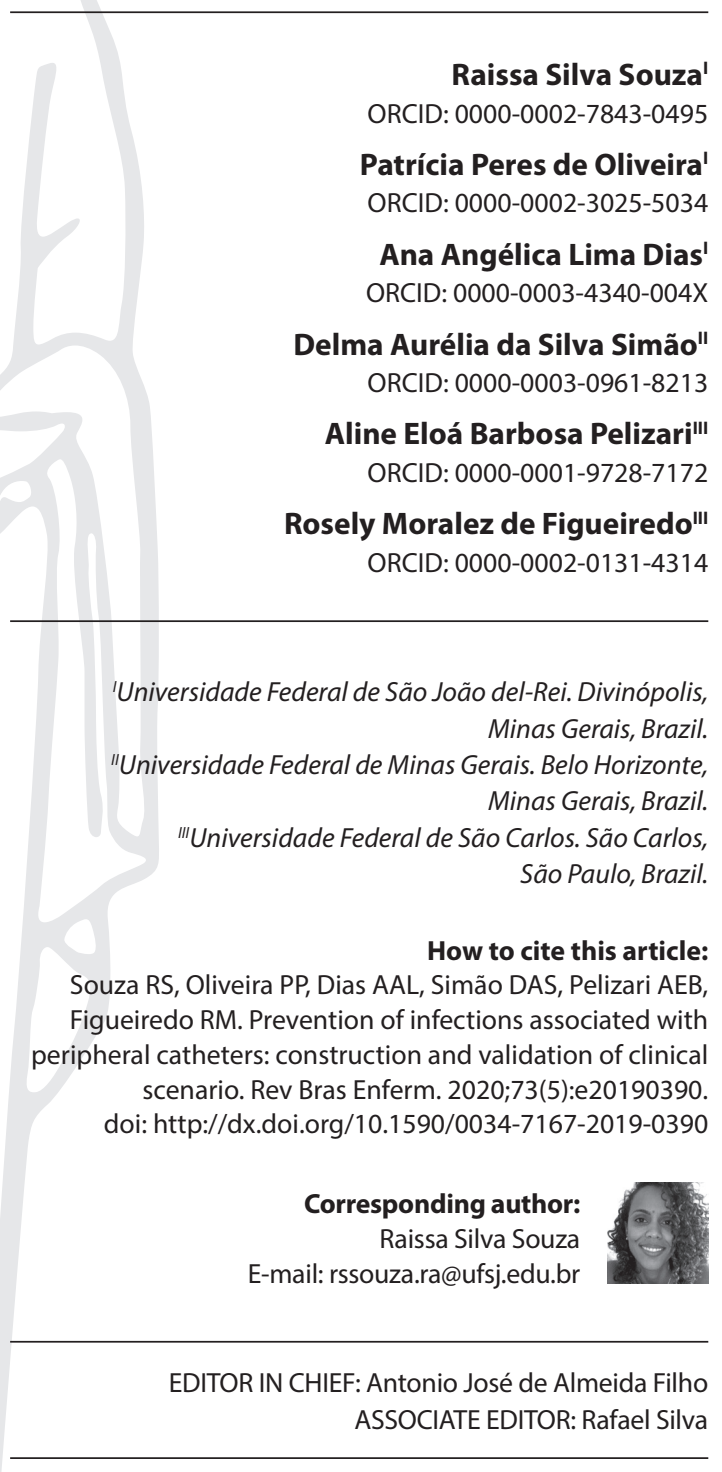

Submission: 08-14-2019

Approval: $03-23-2020$

\section{ABSTRACT}

Objectives: to describe the process of construction and content validation of a clinical setting for teaching and learning the recommended practices for preventing bloodstream infection, associated with peripheral venous catheters, for nursing professionals. Methods: methodological study of the construction of the scenario based on the National League Nursing Jeffries Simulation Theory, International Nursing Association for Clinical Simulation and Learning, and the Brazilian Health Regulatory Agency. Twelve experts performed content validation. We used to assess the degree of agreement between them, the Content Validity Index, and a descriptive analysis of the suggestions presented. Results: all the requirements of the simulated clinical scenario reached an agreement between judges of more than $80 \%$ in terms of clarity and relevance. Conclusions: the steps adopted in the construction and validation of the clinical scenario proved to be adequate and relevant, and the scenario is suitable for training professionals.

Descriptors: Infection Control; Validation Study; Health Education; Simulation Training; Nursing.

\section{RESUMO}

Objetivos: descrever o processo de construção e validação de conteúdo de um cenário clínico para o ensino e aprendizagem das práticas recomendadas de prevenção de infecção de corrente sanguínea, associadas a cateteres venosos periféricos, para profissionais de enfermagem. Métodos: estudo metodológico de construção do cenário pautada na National League Nursing Jeffries Simulation Theory, International Nursing Association for Clinical Simulation and Learning e Agência Nacional de Vigilância Sanitária. A validação de conteúdo foi feita por 12 especialistas. Para aferir o grau de concordância entre eles, utilizou-se o Índice de Validade de Conteúdo e análise descritiva das sugestões apresentadas. Resultados: todos os requisitos do cenário clínico simulado alcançaram concordância entre os juízes superior a $80 \%$ quanto à sua clareza e relevância. Conclusões: os passos adotados no percurso de construção e validação do cenário clínico mostraram-se adequados e relevantes, estando o cenário apto para ser utilizado ao treinamento de profissionais.

Descritores: Controle de Infecções; Estudos de Validação; Educação em Saúde; Simulação; Enfermagem.

\section{RESUMEN}

Objetivos: describirel proceso de construcción y validación de contenido de un escenario clínico para la enseñanza y aprendizaje de las prácticas recomendadas de prevención de infección de la corriente sanguínea, relacionadas a catéteres venosos periféricos, para profesionales de enfermería. Métodos: estudio metodológico de construcción del escenario pautada en la National League Nursing Jeffries Simulation Theory, International Nursing Association for Clinical Simulation and Learning y Agencia Nacional de Vigilancia Sanitaria. La validación de contenido ha sido realizada por 12 especialistas. Para aferir el grado de concordancia entre ellos, se ha utilizado el Índice de Validad de Contenido y análisis descriptivo de las sugestiones presentadas. Resultados: todos los requisitos del escenario clínico simulado alcanzaron concordancia entre los jueces superior a $80 \%$ cuanto a su clareza y relevancia. Conclusiones: los pasos adoptados en el trayecto de construcción y validación del escenario clínico se mostraron adecuados y relevantes, estando el escenario apto para ser utilizado al entrenamiento de profesionales. Descriptores: Control de Infecciones; Estudios de Validación; Enseñanza en Salud; Simulación; Enfermería. 


\section{INTRODUCTION}

Health care-associated infections (HAls) are a severe public health problem worldwide, being considered persistent adverse events in health services and responsible for high rates of morbidity and mortality in this context ${ }^{(1-3)}$. Among the HAls, the progressive increase in bloodstream infections (BSIs) stands out. That is because of the increasing use of invasive devices and procedures for the diagnosis, monitoring, control, and treatment of diseases ${ }^{(4)}$.

BSIs are the infections related to assistance with the highest preventive potential, in which $65 \%$ to $70 \%$ of cases could be prevented with the adoption of appropriate measures regarding the insertion, maintenance and handling of devices by health professionals, especially nurses, directly and continuously involved in patient care with invasive bloodstream devices ${ }^{(1,5-6)}$.

Despite the existence of several publications with guidelines and recommendations for the prevention and control of BSIs, it is clear that the incorporation of this knowledge in the practice of health services has been slow, with late changes in the results and quality of care provided ${ }^{(3,7)}$. This evidence does not mean that there are no teaching movements in service, but that they have been insufficient, unsystematic, based on the theoretical biomedical model and implemented through vertical and decontextualized pedagogical strategies ${ }^{(8)}$.

The adoption of theoretical and pedagogical references that prioritize the involvement and engagement of professionals in their development and qualification process, such as the theory of experiential learning, has demonstrated the potential to change this reality. This theory conceives that, as the persons become able to give meaning to their experiences, reviewing them, and planning the future, they transform themselves and the environment ${ }^{(9)}$.

The materialization of this theoretical proposal in health education can happen through clinical simulation. Such pedagogical strategy centers on the recreation or replication of a set of conditions that resemble real-life situations to train technical skills and critical thinking concerning the professional role that will be played ${ }^{(10)}$.

The effectiveness of the clinical simulation, in terms of teaching, is directly related to the construction of clinical scenarios with an adequately planned plot and the objective of bringing specific learning results to the participants, as well as their validation, proper execution and preparation of those involved ${ }^{(11-13)}$.

Although it is possible to find theoretical models and scripts in the literature explaining the elements that clinical settings for health education must contain ${ }^{(12,14)}$, we did not identify studies that provide such scenarios built on these models and the respective validation process, in particular scenarios focused on the topic of recommended practices for preventing BSIs associated with peripheral catheters.

\section{OBJECTIVES}

To describe the process of construction and content validation of a clinical setting for teaching and learning the recommended practices for preventing BSIs associated with peripheral venous catheters for nursing professionals.

\section{METHODS}

\section{Ethical aspects}

The study was approved by the Human Research Ethics Committee of the Federal University of São João del-Rei (Opinion $2,357,581)$. All participants registered their consent by signing the Free and Informed Consent Form (ICF).

\section{Study design and period}

Descriptive and methodological study with a quantitative approach carried out between September 2017 and June 2018. The study was developed in two stages, namely: construction of the scenario and validation of the content by specialists.

\section{Study location, participants, inclusion, and exclusion criteria}

For the stage of validation of the clinical scenario, a committee of specialist nurses was created, based on the criteria adapted from Fehring ${ }^{(15)}$. It was considered as an inclusion criterion to meet at least one of the following items: specialization course, clinical experience, or having published articles in the area of $\mathrm{HAl}$ or the area of clinical simulation.

For the selection of specialists, we used the non-probabilistic sampling technique "snowball," in which the capture of participants is triggered by the election of the first individuals, who, in turn, indicate new participants from their network of contacts ${ }^{(16)}$. Therefore, we sent an email with an invitation to participate in the study to a professional (key-informant), together with the link to the application for creating custom forms, Google forms ${ }^{\circ}$, for access to the electronic form document containing the ICF, the instrument for characterizing the participants, the instructions for analyzing and registering the responses and the clinical scenario to be analyzed. This key informant was asked to indicate three other professionals who met the study's inclusion criteria. Participants should answer the instrument within 45 days. Of the 16 invited experts, 12 agreed to participate and returned the completed instrument electronically within the stipulated period.

\section{Study Protocol}

The authors' construction of the clinical scenario based on the theoretical model of the National League Nursing Jeffries Simulation Theory (NLN/JST) ${ }^{(17)}$, as well as on the recommended practice standards for the simulation design indicated by the International Nursing Association for Clinical Simulation and Learning (INACSL) ${ }^{(18)}$. Thus, it operated with the conceptual components of the theoretical model, combining them with the items recommended by INACSL. These references can be considered complementary. The first defines the conceptual components of the theoretical model, while the second contemplates the items necessary for the construction of scenarios, according to evidence from the area. The information regarding recommended practices for preventing BSIs associated with peripheral venous catheters arisen from the recommendations of the Brazilian Health Regulatory Agency (ANVISA) ${ }^{(1)}$. 
The conceptual components of NLN/JST ${ }^{(17)}$ are: 1)"context"refers to the set of circumstances that configure the starting point for the development and evaluation of the simulation; 2) "background" covers the objectives, the theoretical perspective that supports the construction of the simulation and other aspects that can influence the design of the simulation as a modality; 3 ) "design" includes everything from elements for the fidelity of the scenario, such as materials and props, to the specific learning objectives that will guide the appropriate selection of scenarios, details of the prebriefing (session for instructing and preparing the participants for the clinical simulation) (10) , "briefing" (session immediately before the start of the scene in which participants receive essential information about the clinical scenario) ${ }^{(10)}$ and debriefing; 4) "simulated experience" refers to the experimental environment that must be created for the simulation, involving interactivity, collaboration and trust; 5) "facilitator and educational strategy" is related to facilitation for the development of simulation based on the assumptions of the strategy; 6 ) "participants" refers to the innate and modifiable attributes that can influence the simulated learning experience; and 7) "results" refers to outcomes for participants, patient and system.

The validation by specialists took place through the platform Google forms ${ }^{\circ}$, and the items of the clinical scenario were evaluated for clarity and relevance. The answers were scored on a 4-point Likert scale, in which 1 corresponded to the item "Unclear/not relevant"; 2 , the"Item needs a major revision to be clear/pertinent"; 3 , Item needs a little revision to be clear/pertinent"; and 4, "clear/pertinent item."The set of items that composed each conceptual component was evaluated for scope, with the options of answers: "Conceptual component not comprehensive $=1$ "; "Conceptual component requires major revision to be comprehensive = 2"; "Conceptual component requires little revision to be comprehensive = 3"; "Conceptual component comprehensive $=4$ ". For the items scored in 1 or 2 , the specialist was asked to justify their response and suggest a new wording.

\section{Analysis of Results}

In the stage of validation of the clinical scenario by the judges, the Content Validity Index (CVI) of the items was calculated by adding the answer options " 3 " and " 4 " and dividing the result by the total number of answers. A CVI equal to or greater than $80 \%$ agreement among specialists was adopted to consider the item validated. An index considered appropriate in the literature ${ }^{(19)}$. We revised the items that did not reach this index according to the indications of the experts.

\section{RESULTS}

Concerning the stage of construction of the clinical simulation, the final scenario, prepared based on the NLN/JST model ${ }^{(17)}$, according to INASCL ${ }^{(18)}$ and in the recommendations of ANVISA ${ }^{(1)}$, contains seven conceptual components subdivided into items: "context,"'"background,"'design,"'"simulated experience,,"facilitator and educational strategy," "participants" and "results".

The conceptual component "context" contains seven items, including the name of the scenario and the proposed course/activity, the target audience, the location for the development of the clinical simulation scenario and the debriefing, the teaching purpose, the purpose of evaluation and the evaluation methods. The conceptual component "background"contains five items that explain the learning objective, the preparation of participants and the educational resources, the time to perform each stage of the clinical simulation, the theoretical perspective adopted, and the simulation modality.

Therefore, the clinical scenario entitled "Prevention of bloodstream infections associated with peripheral venous catheters" aimed at improving knowledge on the prevention of bloodstream infections (BSIs) associated with peripheral venous catheters for the entire nursing team. This scenario had the purpose of teaching to create conditions for the participant to analyze and discuss the prevention measures of BSIs; recognize and discuss the application of measures to prevent BSIs associated with peripheral venous catheters; analyze and synthesize the results of the experience of implementing the prevention measures of BSIs associated with peripheral venous catheters. The evaluation strategies proposed are self-assessment, peer evaluation, direct observation, and feedback by the facilitator (if necessary), and the application of structured instruments for the evaluation of the teaching strategy and knowledge of the participant.

In the material produced, it is expected that the participants of the clinical simulation prepare for the activity by reading the material sent electronically 15 days in advance. The central elements of this material will be discussed with the participants before the beginning of the clinical simulation. The definition of

Chart 1 - Conceptual component "design" of the clinical scenario for teaching the recommended practices of infection prevention associated with catheters, São Carlos, São Paulo, Brazil, 2019

\section{CONCEPTUAL COMPONENT: DESIGN}

Specific objectives: Implement measures to prevent BSIs associated with peripheral catheters; identify weaknesses in the performance of expected actions; list strategies aimed at addressing the weaknesses identified; reflect on the incorporation of BSIs prevention measures in the real context of services.

Team and participants: Mr. John (standardized patient/actor); nurse Joana (actress/lifesaver); professional 1 (a participant who will act in the scenario); observers (up to nine people) facilitator.

Materials, equipment, and props: Stretcher/bed for the patient. Space for the nursing station. Materials for insertion of the peripheral venous catheter. Phlebitis makeup to be positioned in the lower third of the right forearm of the standardized patient. Low fidelity simulator for intravenous injections - arm (Laerdal') (continues).

Fidelity: The simulation will take place in the institution, in a place where the scene can be set up with all the scenic elements detailed in this material. The standardized patient should be lying on the bed/stretcher, wearing clothes worn by the patients in the institution (continues).

Evaluation method: Direct observation and feedback from the facilitator; peer evaluation/co-assessment; self-assessment.

Briefing: 7:30 am. You were admitted to the shift with the information that Mr. John Batista, 30, was admitted in the early hours of the morning, transferred from a hospital in a small neighboring municipality where he remained for two days. He came to continue the treatment of pneumonia with intravenous antibiotic therapy (Ceftriaxone 1 grass, intravenously). A saline solution was used in the peripheral venous access in the lower third, Mr. John's forearm. He has been complaining of pain at the site since his admission to the hospital. The bell in Mr. John's room is ringing, and you are going to go over there and answer the call.

Debriefing: This clinical simulation session aims to enable the analysis of the simulated experience with a view to learning. The time set for this activity is approximately 30 minutes (continues).

Note: $B S I$ - bloodstream infections. 
the time for each of the clinical simulation sessions - preparation, prebriefing, briefing, scenario execution, and debriefing — were pre-established based on the adopted framework.

The conceptual component "design"includes ten items presented in a synthesized form (Chart 1). It is noteworthy that, to guide the session of debriefing, we used as a theoretical model Promoting Excellence and Reflective Learning in Simulation - PEARLS ${ }^{(20)}$.

The clinical scenario constructed fits the modality of realistic clinical simulation, hybrid and of low fidelity, with the participation of a standardized patient (actor) and use of a low fidelity simulator for intravenous injections - arm (Laerdal ${ }^{\circ}$ ), which allows the insertion of a peripheral catheter and the respective blood drainage (liquid introduced in the simulator compartment). The materials and equipment needed for the scenario composition were specified, with attention to including the indication that it would be desirable for them to be similar to those used in the service in which the simulation will take place.

The clinical case created presents a low level of uncertainty, with the availability of only relevant information that could assist the participants in the resolution of the activity and achievement of the objectives. A checklist containing the priority actions to be performed in the case was also prepared. In each action, there was room to indicate whether or not the participant who acts in the case performed it, as well as space for reporting observations. This checklist should be used by the facilitator, to monitor the activity, and the participants who observe the case execution, to guide the observation and instrumentalize the reflections in the debriefing.

The conceptual component "simulated experience" has only one item, which presents the expectations concerning the experience of the clinical simulation. We planned in the elaboration of the scenario, prebriefing, a moment for identifying participants' expectations about the simulation. The conceptual component "facilitator and the educational strategy" brings two items, the first of which presents guidelines for the facilitator of the simulation, and the second presents the characteristics of the theoretical assumption to be operationalized in the educational strategy.

The conceptual component "participants" includes an item, which presents characteristics of the participants that can interfere in the clinical simulation experience, and the facilitator should consider that. Finally, there is the conceptual component "results," with only one item, which lists the expected outcomes with the simulation for the participants, patient, and system. We expect that teaching based on clinical simulation of measures to prevent BSIs associated to peripheral venous catheters, in order to improve the knowledge of nursing professionals, contributes to the satisfaction and self-confidence of the participants, to the awareness of the need to adopt measures to prevent BSIs associated to peripheral catheters in care, and to reduce rates of HAls and to increase the safety of health professionals and patients.

Regarding the stage of validation of the clinical scenario by the 12 specialists who participated in the process, 11 were women; the mean age was 43 years old (minimum age, 27 years; maximum age, 69 years); four participants (33.3\%) had master's degree, six (50\%) had a doctorate, and two (16.7\%) had specializations. Regarding the length of professional experience, nine (74.1\%) had more than ten years of experience. Regarding the area of activity, eight $(66.7 \%)$ acted in teaching and research and four (33.3\%) in management and administrative areas.

The Analysis of the CVI of the items of the conceptual components proposed in the theoretical model presented results greater than $80 \%$ in the evaluation of the specialists regarding their clarity and pertinence, as presented in Table 1.

Table 1 - Result of the content validity index (CVI) of the conceptual components and items of the clinical scenario obtained based on the analysis of the responses of the specialists $(n=12)$, São Carlos, São Paulo, 2019

\begin{tabular}{|c|c|c|c|c|}
\hline Conceptual component & Item & Clarity & Relevance & Results \\
\hline Context & $\begin{array}{l}\text { Course name/strategy } \\
\text { Target Audience } \\
\text { Scenario location and debriefing } \\
\text { Teaching purpose } \\
\text { Evaluation purpose } \\
\text { Evaluation method: } \\
\text { Scope of the conceptual component }\end{array}$ & $\begin{array}{c}100 \% \\
100 \% \\
83 \% \\
100 \% \\
83 \% \\
83 \%\end{array}$ & $\begin{array}{l}100 \% \\
100 \% \\
92 \% \\
100 \% \\
83 \% \\
83 \% \\
75 \%\end{array}$ & $\begin{array}{l}\text { Validated } \\
\text { Validated } \\
\text { Validated } \\
\text { Validated } \\
\text { Validated } \\
\text { Validated } \\
\text { Not validated }\end{array}$ \\
\hline Background & $\begin{array}{l}\text { Learning objective } \\
\text { Participants' preparation } \\
\text { Time } \\
\text { Theoretical perspective } \\
\text { Modality } \\
\text { Scope of the conceptual component }\end{array}$ & $\begin{array}{c}83 \% \\
100 \% \\
100 \% \\
92 \% \\
100 \%\end{array}$ & $\begin{array}{c}83 \% \\
100 \% \\
100 \% \\
83 \% \\
100 \% \\
92 \%\end{array}$ & $\begin{array}{l}\text { Validated } \\
\text { Validated } \\
\text { Validated } \\
\text { Validated } \\
\text { Validated } \\
\text { Validated }\end{array}$ \\
\hline Design & $\begin{array}{l}\text { Specific objectives } \\
\text { Team and participants } \\
\text { Materials and props } \\
\text { Fidelity } \\
\text { Evaluation method } \\
\text { Prebriefing } \\
\text { Briefing } \\
\text { Scene progression } \\
\text { Expected actions } \\
\text { Patient status } \\
\text { Dialogues } \\
\text { Briefing } \\
\text { Scope of the conceptual component }\end{array}$ & $\begin{array}{c}92 \% \\
92 \% \\
92 \% \\
83 \% \\
92 \% \\
100 \% \\
100 \% \\
92 \% \\
92 \% \\
100 \% \\
92 \% \\
100 \%\end{array}$ & $\begin{array}{c}92 \% \\
92 \% \\
92 \% \\
92 \% \\
92 \% \\
100 \% \\
100 \% \\
92 \% \\
92 \% \\
100 \% \\
92 \% \\
100 \% \\
100 \%\end{array}$ & $\begin{array}{l}\text { Validated } \\
\text { Validated } \\
\text { Validated } \\
\text { Validated } \\
\text { Validated } \\
\text { Validated } \\
\text { Validated } \\
\text { Validated } \\
\text { Validated } \\
\text { Validated } \\
\text { Validated } \\
\text { Validated } \\
\text { Validated }\end{array}$ \\
\hline
\end{tabular}


Table 1 (concluded)

\begin{tabular}{|c|c|c|c|c|}
\hline Conceptual component & Item & Clarity & Relevance & Results \\
\hline Simulated experiment & $\begin{array}{l}\text { Simulated experiment } \\
\text { Scope of the conceptual component }\end{array}$ & $92 \%$ & $\begin{array}{l}92 \% \\
92 \%\end{array}$ & $\begin{array}{l}\text { Validated } \\
\text { Validated }\end{array}$ \\
\hline Facilitator and Educational Strategy & $\begin{array}{l}\text { Facilitator } \\
\text { Educational Strategy } \\
\text { Scope }\end{array}$ & $\begin{array}{l}100 \% \\
100 \%\end{array}$ & $\begin{array}{l}100 \% \\
100 \% \\
100 \%\end{array}$ & $\begin{array}{l}\text { Validated } \\
\text { Validated } \\
\text { Validated }\end{array}$ \\
\hline Participant & $\begin{array}{l}\text { Characteristics that may interfere with the experience } \\
\text { Scope of the conceptual component }\end{array}$ & $100 \%$ & $\begin{array}{l}100 \% \\
100 \%\end{array}$ & $\begin{array}{l}\text { Validated } \\
\text { Validated }\end{array}$ \\
\hline Results & $\begin{array}{l}\text { Expected Results } \\
\text { Scope of the conceptual component }\end{array}$ & $100 \%$ & $\begin{array}{l}100 \% \\
100 \%\end{array}$ & $\begin{array}{l}\text { Validated } \\
\text { Validated }\end{array}$ \\
\hline
\end{tabular}

Regarding the analysis of the scope $(A)$ of the conceptual components, only the "context" obtained CVI lower than 80\% (A $=75 \%)$. We accepted the experts' suggestion about the minor adjustments (spelling corrections, synonyms use, sequence and detailing of the text changing) as well as the most significant ones, such as flexibilization of the place to perform the scenario and debriefing and detailing of the central focus of the activity, regardless of the CVI. It is noteworthy that the items contained in the initial version remained the same in the final version, with the appropriate adjustments.

One of the modifications made was in the item that contained the specification of the site for clinical simulation. The initial proposition was that the simulation should be performed in situ, that is, in the very place where the assistance takes place - for example, in a vacant room in the service unit itself. This proposition was considered inappropriate, as it could make it impossible to perform the activity in institutions with a high occupancy rate and bed turnover. We decided to make this specification more flexible.

Another point also mentioned by the experts was concerning the evaluation. They proposed the elaboration of an instrument to measure participants' knowledge on the theme, to be applied before and after the simulation.

\section{DISCUSSION}

The reconciliation of the NLN/JST model and the standards of INASCL enabled structuring a clinical scenario with a sequence of learning activities involving decision-making, problem-solving strategies, reasoning, and distinct cognitive abilities. Such attributes are necessary when there is the intention of proposing professional qualification activities to enable the transposition of skills and knowledge developed in the learning environment of professional practice ${ }^{(21)}$. Also, the realization of experiential educational practices, with contextual meaning and active participation of the professional, enables critical reflection on the care provided and the (re)option for the best evidence for practices in the daily routine of services ${ }^{(21)}$.

Moreover, we understand that the clinical scenario created outlined a simple decision environment ${ }^{(22)}$, in which the mental functions of conceiving, judging, and reasoning will be triggered ${ }^{(23)}$. Corroborating another author ${ }^{(12)}$, we consider that it was possible to respect the principles of simplicity, objectivity, brevity, reality, and comprehensiveness in this clinical simulation ${ }^{(12)}$. We believe that these characteristics favor the reproducibility of this simulation by nursing professionals, also providing opportunities for the standardization of the recommended practices of prevention of BSIs in the process of peripheral venous catheters insertion in services ${ }^{(21)}$.

Regarding the teaching purposes established for the clinical scenario constructed, we sought to elaborate them so that they could be measured, as well as the specific objectives listed. Stipulating the objectives of clinical simulation beforehand helps in the dimensioning of the time required for the activity. Furthermore, making it available to participants is strongly recommended in the literature ${ }^{(24)}$.

We decided to indicate, in the scenario, the prior preparation of the participants for the clinical simulation experience since there is evidence that providing them with knowledge about the object covered in the simulation enables their engagement in the activity, as well as creates conditions for the application of knowledge in real clinical practice, favoring the achievement of an effective learning experience ${ }^{(12,21)}$. We recommended the provision of materials and preparation resources in order to develop an understanding of the concepts and content related to simulation ${ }^{(18)}$.

As for the design of clinical simulation, we understand that realism is crucial for the success of the activity, requiring meticulous attention to the elements of the scenario, such as the choice of inputs, equipment, and simulators ${ }^{(21)}$. The option for mixed simulation method, with the participation of an empowered person interpreting the standardized patient, enhances the realism of the scenario since it creates conditions for the development of competencies inherent to human interaction, communication, and empathy, as well as specific technical skills and decision-making ${ }^{(14)}$.

In clinical simulations that choose standardized patient participation, its characterization, with moulage, clothing, and accessories similar to those used in real conditions, promotes the realism of the scenario ${ }^{(12,24)}$. In the proposed clinical scenario, the complete description of the characterization of the standardized patient, as well as the detailing of the patient's life and health history, previous and current, are presented.

The use of low fidelity simulators, like the one chosen for this scenario, makes the activity more accessible, relatively low cost and simple maintenance, enabling the performance of this type of activity in the context of health services ${ }^{(25)}$. All these elements put together to create conditions for the immersion of the participant and enable the cognitive connection between theory and practice. However, we recognized that the achievement of the objectives and results of the clinical simulation does not depend exclusively on these elements, but also the proper planning and assertive conduct of the facilitator ${ }^{(21)}$.

In the present study, the facilitator of the simulation and the participants who observed the execution of the scenario used 
a structured checklist. It was an alternative to instrumentalize them in the development of their roles. Specialists recommend the use of this type of tool in the study on script construction for simulation ${ }^{(12)}$.

The evaluation strategies contemplated in the clinical scenario - a direct observation with feedback from the facilitator (when necessary), peer evaluation and self-assessment, all performed orally in the debriefing - are based on a developmental and procedural perspective. They connect, as recommended in the literature, to the learning objectives and complexity of the scenario, having, such strategies, the ultimate purpose of creating conditions conducive to the development and improvement of learning ${ }^{(12)}$. Studies have been using validated instruments for the participant's evaluation to measure other aspects of the simulation, such as self-perception of the participant's levels of self-confidence and satisfaction ${ }^{(24,26)}$.

The script of the constructed debriefing, inspired by PEARLS ${ }^{(20)}$, enables the integration of educational strategies of participants' self-assessment, focused discussion, and provision of information in the form of directive feedback, opportune for the clinical simulation constructed and tested in this study. This script includes guiding questions working as a trigger for participants expressing their initial reactions, as well as for describing the relevant elements of the case, analyzing the well-performed activities, and those that could be differently performed if there was a new opportunity to perform the same scenario. In the end, the participant is guided to briefly express the lessons/teachings learned and how they would apply in their practice. The existence of a script for debriefing enables the facilitator to play its role properly. Besides, it allows people with little experience in this teaching strategy to execute it safely ${ }^{(20)}$.

Although the proposed clinical simulation covers the elements necessary for its achievement, it is worth remembering that it is essential that the facilitator, responsible for conducting the activity, is adequately prepared to perform it. The domain and experience in the clinical activity that will be simulated, as well as the mastery of information and communication technologies and the capacity of acts of dramatization, are scored as key elements for the conduction of the clinical simulation activity. The literature indicates the training of the facilitators by specialists in the subject as well as the continuous updating, given their qualifications, to properly use this teaching strategy ${ }^{(12)}$.

In addition to the importance of enabling the facilitators to conduct the clinical simulation activity properly, they must identify and list, regarding the participants, the innate attributes (such as age, gender, anxiety level, and others) and modifiable attributes (such as preparation for simulation) that can interfere in the simulation experience. This action is important as it should be properly handled in order not to compromise the achievement of the objectives of the simulation ${ }^{(17)}$.

Regarding the results of the learning and improvement process through clinical simulation, we longed for, according to recommendations ${ }^{(17)}$, more direct gains for participants, such as personal satisfaction, self-confidence, and improvement of knowledge, skills, and attitudes. These will also have repercussions on the patient and the health system since they will enable the improvement and qualification of care in the real context of health services. In this sense, we believe that presenting to the institution's heads the data on the potential impact of the activity on the objectives of quality of care and patient safety can foster the adoption of the clinical simulation strategy for the improvement of professionals in different subjects ${ }^{(27)}$.

It is noteworthy that the existence of a simulated scenario script detailing all activities favors the use of the material by people who did not participate in the elaboration of scenario ${ }^{(25)}$ and also by those with little experience in simulation, enabling it to be replicated in institutions where this practice is not usual.

The scenario elaborated was forwarded for validation by experts to ensure that there were no misunderstandings. Thus, it was possible to certify that the material had physical, psychological, and conceptual fidelity ${ }^{(18)}$. Performing the validation of clinical scenarios is strongly recommended, given the achievement of the effectiveness of the teaching and learning experience based on simulation and the quality assurance of its replication ${ }^{(12,18)}$. The analyses of the specialists allowed the refinement of the material produced, resulting in a clinical scenario with more adjusted control of the variables that could compromise the performance of the activity.

Regarding experts' indications about necessary changes in the scenario produced, we understand that the flexibilization of the place of activity - in situ or not - assumed by the authors in the final version of the scenario, on the one hand, favors the performance of the activity of professional improvement, even in contexts in which it is not possible to use an unoccupied bed due to the high turnover and high rate of occupation of the beds. However, on the other hand, without proper adaptations, such flexibilization of the site can compromise the fidelity and realism of the scenario, reflecting on the results.

The realization of the simulation in situ presents several potentialities, among them the possibility of identifying real obstacles that can impact daily care, such as errors of understanding the application of protocols, limitations in physical structure and material resources, as well as communication problems between colleagues. However, the choice for simulation in situ must be the result of an institutional decision, since its implementation involves the use of physical, material, human and financial resources, besides which it can influence the work routine of professionals if it occurs during the work shift ${ }^{(27)}$.

The full material is available with the authors of the study.

\section{Study limitations}

The study has limitations, such as the fact that the clinical scenario has not been tested in situ, that is, in the work environment where the care takes place, or in a simulation laboratory.

\section{Contributions to the nursing field}

The clinical scenario for the teaching and learning process of the recommended practices of prevention of catheter-associated bloodstream infection, validated for nursing professionals, represents an important contribution to in-service teaching of prevention measures of BSIs since it is a simple instrument, of easy replication, low cost and flexible to necessary contextual 
adjustments. We believe that the availability of this clinical scenario makes it possible to create adequate conditions for cognitive, psychomotor, and affective experiences consistent with the proposed learning objectives. Also, we acknowledge that the present study can promote the use of clinical simulation as an efficient and assertive teaching strategy of BSIs prevention measures in the daily routine of health services.

\section{CONCLUSIONS}

The construction of a simulated clinical scenario following a theoretical framework and the recommended practices in simulation allowed the composition of all essential elements to the clinical simulation. The validation of content by the experts, on the other hand, sharpened a higher quality of the information, because its weightings allowed the improvement of the material produced, through adjustments of variables that could compromise the performance of the activity. The steps adopted in the construction and validation of the clinical scenario proved to be adequate and relevant, and the scenario is suitable for training professionals.
The construction and validation of clinical scenarios require time and theoretical deepening, which often limits the use of simulation in academic training and research. The use of previously prepared and validated scenarios in the improvement of nursing team professionals brings gains for professionals, patients, and the health system, reflecting on qualification and safety of care.

\section{FUNDING}

Thanks to the Coordination for the Improvement of Higher Education Personnel (CAPES - Coordenação de Aperfeiçoamento de Pessoal de Nível Superior) for financial support for this study.

\section{ACKNOWLEDGMENT}

Special thanks to the undergraduate nursing students at the Federal University of São João del-Rei (UFSJ) Renato Fernando de Jesus and Cassia Menezes and the undergraduate nursing course at the Federal University of São Carlos (UFSCar) Giovanna da Silva Ferreira, Jônatas Sneideris and Paulo Gustavo Souza.

\section{REFERENCES}

1. Ministério da Saúde (BR). Agência Nacional de Vigilância Sanitária. Segurança do paciente e qualidade em serviços de saúde. Medidas de prevenção de infecção relacionada à assistência à saúde vol. 4[Internet]. Brasília, DF: Ministério da Saúde; 2017 [cited 2019 Apr 02]. 92p. Available from: http://portal.anvisa.gov.br/documents/33852/3507912/Caderno+4++Medidas+de+Preven\%C3\%A7\%C3\%A3o+de+Infec\% C3\%A7\%C3\%A30+Relacionada+\%C3\%A0+Assist\%C3\%AAncia+\%C3\%A0+Sa\%C3\%BAde/a3f23dfb-2c54-4e64-881c-fccf9220c373

2. Oliveira SN, Massaroli A, Martini JG, Rodrigues J. From theory to practice, operating the clinical simulation in Nursing teaching. Rev Bras Enferm. 2018;71(Suppl 4):1791-8. doi: 10.1590/0034-7167-2017-0180

3. Padoveze MC, Juskevicius LF, Santos TR, Nichiata LI, Ciosak SI, Bertolozzi MR. The concept of vulnerability applied to Healthcare-associated Infections. Rev Bras Enferm. 2019;72(1):299-303. doi: 10.1590/0034-7167-2017-0584

4. Nascimento DO, Santos LA. Infecção relacionada à saúde: percepção dos profissionais de saúde sobre seu controle. Rev Interdiscip[Internet]. 2016 [cited 2018 Apr 12];9(2):127-35. Available from: https://revistainterdisciplinar.uninovafapi.edu.br/index.php/revinter/article/view/929/ pdf_318

5. Centers for Disease Control and Prevention-CDC. Guidelines of National and State Healthcare Associated Infections [Internet]. CDC; 2016 [cited 2018 Apr 12];147p. Available from: http://cdc.gov/HAl/pdfs/progress-report/hai-progress-report.pdf

6. European Centers for Disease Prevention and Control. Report on prevention and control of Healthcare-associated infeccions (HAI) [Internet]. ECDPC; 2016 [cited 2018 Apr 12]. Available from:http://ecdc.europa.eu/en/healththopics/Healthcare-associated_infeccions/Pages/index. aspx\#sthash.qthj6qOr.dpuf

7. Bauer MS, Damschroder L, Hagedorn H, Smith J, Kilbournes AM. An introduction to implementation science for the non-specialist. BMC Psychol [Internet]. 2015 [cited 2018 Apr 12];3:32. Available from: https://www.ncbi.nlm.nih.gov/pmc/articles/PMC4573926/

8. Soares NA, Souza V, Santos FBO, Carneiro ACLL, Gazzinelli MF. Health education device: reflections on educational practices in primary care and nursing training. Texto Contexto Enferm. 2017;26(3):e0260016. doi: 10.1590/0104-07072017000260016

9. Pimentel A. A teoria da aprendizagem experiencial como alicerce de estudos sobre desenvolvimento profissional. Estud Psicol. 2007;12(2):159-68. doi: 10.1590/S1413-294X2007000200008

10. Lopreiato JO, (Ed.). Terminology \& Concepts Working Group. Healthcare Simulation Dictionary [Internet]. Orlando: SSH; 2016 [cited 2016 Aug 15]. Available from: http://www.ssih.org/dictionary

11. Rutherford-Hemming T. Determining contente valdity and reporting a content validity index for simulation scenarios. Nurs Educ Perspect. 2015;36(6):389-93. doi: 10.5480/15-1640

12. Fabri RP, Mazzo A, Martins JCA, Fonseca AS, Pedersoli CE, Miranda FBG, et al. Development of a theoretical-practical script for clinical simulation. Rev Esc Enferm USP. 2017;51:e03218. doi: 10.1590/S1980-220X2016016403218

13. Alinier G. Developing high-fidelity health care simulation scenarios: a guide for educators and professionals. Simul Gaming. 2011;42(1): 9-26. doi: $10.1177 / 1046878109355683$

14. Cioffi J. Clinical simulations: development and validation. Nurs Educ Today. 2001;21:477-86. 10.1054/nedt.2001.0584 
15. Fehring RJ. The Fehring model. In: Carrol-Johnson RM, Paquete M. Classification of nursing diagnoses: proceeding of the tenth conference. Philadelphia, EUA: Lippincott Company; 1994. p.55-62.

16. Colin ECS, Pelicioni MCF. Territorialidade, desenvolvimento local e promoção da saúde: estudo de caso em uma vila histórica de Santo André, São Paulo. Saude Soc. 2018;27(4):1246-60. 10.1590/s0104-12902018170850

17. Jeffries PR, Rodgers B, Adamson K. NLN Jeffries simulation theory: brief narrative description. Nurs Educ Perspect. 2015;23(5):292-5. doi: 10.5480/1536-5026-36.5.292

18. International Nursing Association for Clinical Simulation and Learning. Clinical simulation in nursing [Internet]. Florida: INACSL; 2016 [cited 2018 Apr 30]. Available from: http://www.nursingsimulation.org/

19. Coluci MZO, Alexandre NMC, Milani D. Construção de instrumentos de medida na área da saúde. Ciênc Saúde Coletiva. 2015;20(3):925-36. doi: 10.1590/1413-81232015203.04332013

20. Eppich W, Cheng A. Promoting Excellence and Reflective Learning in Simulation (PEARLS): development and rationale for a blended approach to health care simulation debriefing society for simulation in healthcare. Simul Healthc. 2015;10(2):106-15. doi: 10.1097/ $\mathrm{SIH} .0000000000000072$

21. Robinson BK, Dearmon V. Evidence-based nursing education: effective use of instructional design and simulated learning environments to enhance knowledge transfer in undergraduate nursing students. J Prof Nurs. 2013;29(4):203-9. doi: 10.1016/j.profnurs.2012.04.022

22. Mesquita HCT, Santana BS, Magro MCS. Effect of realistic simulation combined to theory on self-confidence and satisfaction of nursing professionals. Esc Anna Nery. 2019;23(1): e20180270. doi: 10.1590/2177-9465-ean-2018-0270

23. Carvalho EC, Oliveira-Kumakura ARS, Morais SCRV. Clinical reasoning in nursing: teaching strategies and assessment tools. Rev Bras Enferm. 2017;70(3):662-8. doi: 10.1590/0034-7167-2016-0509

24. Kaneko RMU, Lopes MHBM. Realistic health care simulation scenario: what is relevant for its design? Rev Esc Enferm USP. 2019;53:e03453. doi: 10.1590/S1980-220X2018015703453

25. Meska MHG, Mazzo A, Jorge BM, Souza-Jr VD, Negri EC, Chayamiti EMPC. Urinary retention: implications of low-fidelity simulation training on the self-confidence of nurses. Rev Esc Enferm USP. 2016;50(5):831-37. doi: 10.1590/S0080-623420160000600017

26. Almeida RGS, Mazzo A, Martins JCA, Pedersoli CE, Fumincelli L, Mendes ISC. Validation for the portuguese language of the simulation design scale. Texto Contexto Enferm. 2015;4(24):934-40. doi: 10.1590/0104-0707201500004570014

27. Alkhulaif A, Julie I, Barton J, Nagle E, Yao A, Clarke S, et al. Simulación in situ: ventajas, retos y obstáculos. Latin Am J Telehealth[Internet]. 2016[cited 2016 Aug 15];3(2):141-9. Available from: http://cetes.medicina.ufmg.br/revista/index.php/rlat/article/download/139/292/ 